\title{
La obsolescencia de las tipologías de vivienda de los polígonos residenciales construidos entre 1950 y 1976. Desajustes con la realidad sociocultural contemporánea
}

\author{
Housing typologies obsolescence of the residential estates built between 1950 \\ and 1976. Mismatches with contemporary socio-cultural reality
}

C. García Vázquez ${ }^{(*)}$

\section{RESUMEN}

El artículo se centra en una de las causas de la actual obsolescencia de los denominados «polígonos residenciales»: la que tiene que ver con las tipologías de vivienda. Al tratarse de un proceso controlado y dirigido por el estado, éstas son relativamente unitarias, obedeciendo a decretos, reglamentos y regulaciones dictados por el gobierno sobre todo en la década de 1950. El autor detecta en las opciones tipológicas de estas normativas graves desencuentros con la realidad sociocultural contemporánea, avanzando la hipótesis de que aquéllas son uno de los motores del citado estado de obsolescencia. El artículo se estructura en dos apartados: el primero repasa el proceso de reflexión y experimentación que antecedió a la producción en masa de los polígonos residenciales en las décadas de 1960 y 1970; el segundo delinea los principales desajustes existentes entre sus tipologías arquitectónicas y las necesidades contemporáneas.

Palabras clave: Obsolescencia urbana; polígonos residenciales; vivienda social; arquitectura franquista.

\section{ABSTRACT}

The paper focuses on housing typologies as one of the main reasons for the current obsolescence of the so called "poligonos residenciales". These housing estates were relatively homogeneous, due to the fact that they were the result of processes determined and controlled by the government through laws, norms and regulations, mostly during the decade of the 1950s. The author contends that the architectural typologies derived from these prescriptions contribute to their obsolescence because nowadays they present a mismatch with contemporary social and cultural reality. The article is structured around two points. The first one reflects upon the evolution of the thinking and the process of experimentation that preceded the mass construction of the "poligonos residenciales" in the 196os and 1970s. The second one identifies and discusses five main mismatches between their housing typologies and contemporary needs.

Keywords: Urban obsolescence; housing estates; social housing; architecture during Franco’s regime.

(*) Escuela Técnica Superior de Arquitectura, Universidad de Sevilla. Sevilla (España). Persona de contacto/Corresponding author: ccggvv@us.es (C. García Vázquez)

Cómo citar este artículo/Citation: García Vázquez, C. (2015). La obsolescencia de las tipologías de vivienda de los polígonos residenciales construidos entre 1950 y 1976. Desajustes con la realidad sociocultural contemporánea. Informes de la Construcción, 67(EXTRA-1): mo20, doi: http://dx.doi.org/10.3989/ic.14.045.

Licencia/License: Salvo indicación contraria, todos los contenidos de la edición electrónica de Informes de la Construcción se distribuyen bajo una licencia de uso y distribución Creative Commons Reconocimiento no Comercial 3.o. España (cc-by-nc). 


\section{INTRODUCCIÓN}

La obsolescencia de la periferia es uno de los más novedosos retos que han de afrontar las administraciones públicas contemporáneas, hasta hace poco mayormente preocupadas por la degradación de los centros históricos. De la Crisis del Petróleo de 1973 se derivó la primera generación de áreas periféricas obsoletas: las industriales. A ella se ha sumado, en los últimos años, la de las barriadas residenciales construidas en la postguerra.

Los gobiernos han comenzado a implementar organismos para analizar y reflexionar sobre esta cuestión. En Francia destaca la labor del Observatoire National des Zones Urbaines Sensibles (ONZUS), y en el Reino Unido la de la de la oficina de planeamiento Design for London. Esta osamenta intelectual ha facilitado soporte conceptual a intervenciones tan emblemáticas como las de Park Hill en Londres (2011), Le Lignon en Ginebra (2009), La Viste en Marsella (2014), Le Grande Parc en Burdeos (2011), o Bois-le-Prête, Les Courtilliéres y La Grande Borne en París (entre 2011 y 2014).

A pesar de contar con casos de referencia internacional, como el del barcelonés barrio de La Mina (2012), España adolece de un desfase en el análisis y teorización de la obsolescencia de las barriadas residenciales. Las intervenciones, normalmente ejecutadas con el apremio de la urgencia social, se han sucedido sin la asistencia de un soporte teórico-conceptual que aportase criterios unitarios o herramientas sistematizables, lo que ha generado un disperso y desorientado elenco de casuísticas y medidas, muchas de ellas socialmente fallidas o económicamente insostenibles.

Esta situación ha animado al mundo académico a involucrarse en el problema, asumiendo el reto de investigar soluciones flexibles y sistematizables, a la vez que inspiradas por sistemas de valores socialmente comprometidos. Este artículo se inserta en esa empresa. Deriva de un proyecto $\mathrm{I}+\mathrm{D}+\mathrm{i}$ denominado «Intervención en barriadas residenciales obsoletas: Manual de Buenas Prácticas», proyecto puesto en marcha por dos grupos de investigación de la Universidad de Sevilla y financiado por la Consejería de Fomento y Vivienda de la Junta de Andalucía, y la Unión Europea.

La hipótesis de partida es que uno de los principales motores de la citada obsolescencia es la inadecuación de las tipologías arquitectónicas de estas barriadas a los requisitos y expectativas de la sociedad contemporánea. Para verificarla, el artículo se estructura en dos apartados. El primero utiliza el análisis histórico para conocer el «cuerpo cierto» de la investigación, realizando un repaso sintético de las condiciones en las que fraguaron dichos conjuntos, y haciendo especial hincapié en las regulaciones legales que determinaron sus tipologías arquitectónicas. El segundo apartado contrasta la información resultante con conclusiones extraídas de un estudio sobre el habitar contemporáneo, analizando el desencaje existente entre la espacialidad de las viviendas de las barriadas y las necesidades de nuestra sociedad. Finalmente, y a modo de conclusión, se esbozan las fortalezas y debilidades con las que habría que contar a la hora de su rehabilitación.

\section{LAS POLÍTICAS DE CONSTRUCCIÓN DE VIVIENDAS SOCIALES EN LA DÉCADA DE 1950}

En España, el «cuerpo cierto» de la investigación que nos ocupa nos remite a las promociones de viviendas sociales construidas durante el franquismo, más concretamente entre 1939, con la aprobación de la Ley de Viviendas Protegidas, y 1976, año de finalización del último Plan Nacional de Vivienda redactado por la dictadura. En este arco temporal destaca la década de 1950, cuando se pusieron las bases conceptuales y administrativas de los denominados "polígonos residenciales», un modelo urbanístico-arquitectónico masivamente implantado durante los años 1960 y 1970.

Los estudios históricos relativos a este tema han proliferado en los últimos tres lustros, espoleados por un interesante proceso de revisión de la arquitectura construida durante el franquismo y por el renacimiento del interés por la cuestión de la vivienda social. Es de reseñar que las publicaciones que han abordado esta etapa de manera más o menos holística se han caracterizado por la especificidad de contenidos, ya sea geográfica (1) (2) (3) o temática (4) (5). Este primer apartado es el resultado de una revisión de dicha bibliografía, en la que se han filtrado los estudios referentes a la década de 1950 y que aluden a cuestiones tipológicas. Ello se ha complementado con un examen de las regulaciones y legislaciones sobre vivienda pública aprobadas en el citado periodo (6).

\subsection{9-1953, la reflexión}

En 1949 se puso en marcha el I Plan Nacional de Vivienda, redactado por José Antonio Girón. La anunciada «revolución de las casas baratas» se confió a un sinnúmero de entidades oficiales. En 1939 se habían creado la Obra Sindical del Hogar (OSH) (7) y el Instituto Nacional de la Vivienda (INV), cuyas ordenanzas eran de aplicación en la OSH. Aparte estaban el Patronato de Casas Militares, el Patronato de Funcionarios, los ayuntamientos, las diputaciones... a los que había que sumar la iglesia católica y entidades afines. La fragmentación de la gestión no era el único escollo al que se enfrentaba el Plan Girón. También estaba la escasez de materiales de construcción, que había obligado al estado a intervenir el sector para garantizar los mínimos necesarios para sus actuaciones prioritarias; y la persistencia de las técnicas artesanales (a finales de los años 1940 las estructuras seguían ejecutándose con muros de carga).

Ante tamañas dificultades, no es de extrañar que el Plan Girón no despertase expectativas entre los arquitectos. Conscientes de su inviabilidad, optaron por centrarse en la reflexión teórica, una tarea no menos apremiante. Desde la llegada del régimen al poder, el debate en torno a la vivienda social se había producido de manera esporádica y no sistemática. Ello había generado un desencuentro entre necesidades y propuestas que dio lugar a que muchas de las promovidas, algunas de ellas de $200 \mathrm{~m}^{2}$ de superficie, no fueran aptas para ser alquiladas, y mucho menos vendidas, a las clases que las necesitaban.

El texto que abrió la etapa de reflexión, en 1949, fue el «Estudio sobre la vivienda económica en España», presentado a

\footnotetext{
Grupos HUM-666 (Ciudad, Arquitectura y Patrimonio Contemporáneos) y TEP-13o (Arquitectura, Patrimonio y Sostenibilidad: Acústica, Iluminación y Energía).
} 
la V Asamblea Nacional de Arquitectos por Ricardo Bastida y Emiliano Amann en nombre del Colegio Oficial de Arquitectos Vasco-Navarro. Esta ponencia proponía un plan de vivienda para la provincia de Vizcaya pero, tal como expone Ana Azpiri (8), acabó transcendiendo con creces ese ámbito geográfico. Teniendo en cuenta el contexto histórico en que se insertaba, llama la atención la racionalidad que condujo esta investigación: una serie de plantas-tipo soportadas por un exhaustivo análisis de necesidades, costes, superficies, funcionalidades, tipologías y sistemas constructivos. Dependiendo del salario del futuro inquilino y del número de componentes familiares, la propuesta aconsejaba superficies máximas que oscilaban entre los $40 \mathrm{~m}^{2}$ para uno o dos ocupantes sin descendientes y los $65 \mathrm{~m}^{2}$ para una pareja con cuatro o cinco hijos. Las plantas se optimizaban espacialmente con estrategias como la supresión de pasillos o la fusión de cocina, estar y comedor en una misma estancia (Figura 1).

La ponencia de Bastida y Amann sentó las bases del debate sobre vivienda social en España. Tres años después de su presentación, en la VI Asamblea Nacional de Arquitectos, Miguel Fisac tomó el testigo con un primer estudio general sobre superficies. Su propuesta era: $30 \mathrm{~m}^{2}$ para familias con un hijo, $36 \mathrm{~m}^{2}$ para familias con dos a cuatro hijos y $40 \mathrm{~m}^{2}$ para familias con cinco o seis hijos. Ello suponía una significativa reducción de estándares con respecto a la proposición vasco-navarra, un hecho que ponía de manifiesto que la maximización de superficies era prioritaria frente a cuestiones como la funcionalidad o la tecnología. La urgencia de la realidad nacional así lo aconsejaba. Para que esta reducción no pusiera en crisis los requisitos mínimos de habitabilidad, Fisac insistía en los presupuestos ya formulados por Bastida y Amann: por un lado agrupar estar, comedor y cocina en una misma sala; por otro suprimir pasillos y vestíbulos.

Estas propuestas cayeron en saco roto. Desgraciadamente, el laboratorio de ideas que acababan de inaugurar no llamó la atención de la administración franquista, para la que el tema de la vivienda popular tan solo era una estrategia para reciclar a las masas campesinas, reducir el desempleo y dinamizar la actividad empresarial. De esta desconexión prácticateoría daban buena nota dos cuestiones: la de la escala y la de la tipología. Por lo que se refiere a la primera, la mayoría de actuaciones llevadas a cabo entre 1949 y 1953 se caracterizó
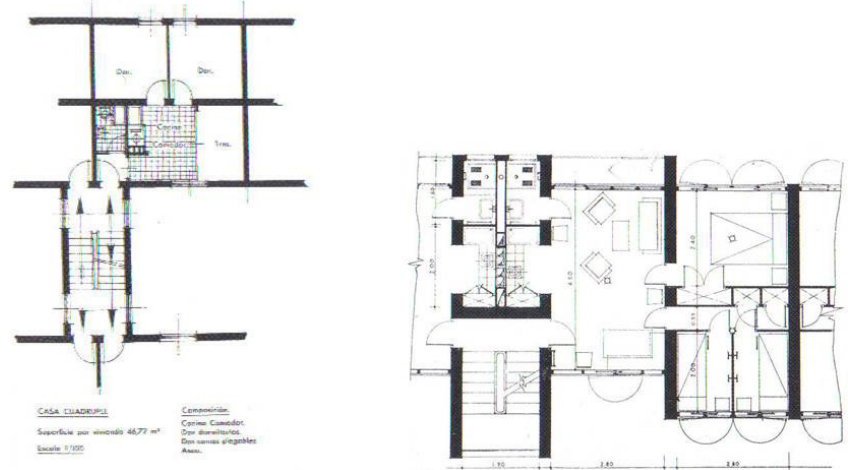

Figura 1. V Asamblea Nacional de Arquitectos (1949): propuestas del Colegio Vasco-Navarro y del Colegio de Madrid, esta última de Miguel Fisac (4). por la pequeña dimensión, lo que ponía en evidencia un incorrecto enjuiciamiento del problema. Traducido a los términos definidos por el III Congreso Internacional de Arquitectura Moderna (CIAM), celebrado en Bruselas en 1930, podríamos asociarlas al concepto de "casa baja ${ }^{2}$. Cuando se optaba por el bloque, éste no solía superar las cuatro plantas, normalmente adosado a otros para conformar manzanas cerradas en torno a patios, el modelo recomendado por Pedro Bidagor en sus planes urbanísticos. Por último, los bloques eran de doble crujía, un esquema derivado de disponer tres muros de carga en paralelo.

\subsection{4-1956, la experimentación}

En 1953 se cerró una etapa: la de la falta de conciencia sobre el problema de la vivienda social. Ese mismo año se firmó el «Pacto Americano», un acuerdo entre Franco y Eisenhower que comprometía ayuda económica estadounidense a cambio del uso de las bases aéreas de Rota, Morón, Zaragoza y Torrejón. Concluía el aislamiento internacional de España, que en 1955 era admitida en la ONU. Estas circunstancias dieron paso a una nueva fase económica que se caracterizaría por la apuesta por la industrialización, lo que indujo, en la cuestión que nos ocupa, la modernización de paradigmas teóricos y procesos constructivos. Tal como defiende Carlos Sambricio: «1954 supone un singular punto de inflexión en la valoración de la vivienda social en los años de la reconstrucción. Asumiendo la idea de «los momentos cortos» en pocos años acontecen cambios sobre la forma de entender y valorar qué debe ser la vivienda social» (9).

Efectivamente, en 1954 el proceso de construcción se aceleró como resultado del crecimiento económico y la definitiva toma de conciencia del régimen. Testimonio de ello fue la aprobación, en 15 días, de dos planes nacionales de vivienda. El 14 de mayo de 1954 entró en vigor el Plan de Vivienda de Tipo Social, que encargaba al INV construir 10.000 unidades. Para las denominadas como «tipo social» prescribía una superficie de $42 \mathrm{~m}^{2}$, y un equipamiento de cocina-comedor-estar y tres dormitorios. Todo ello con un presupuesto de 25.000 pesetas, cifra realmente ajustada si tenemos en cuenta que en aquel momento el coste medio de una vivienda de características similares era de 90.000 pesetas. El 29 de mayo apareció el Plan Sindical de la Vivienda Francisco Franco, encargado a la OSH.

El régimen era consciente de que una de las rémoras para la ejecución de estos planes era la fragmentación administrativa, por lo que centralizó la construcción de viviendas en el INV. En 1954, Luis Valero Bermejo fue nombrado Director General del mismo y, por ende, Jefe Nacional de la OSH. A pesar de la potenciación del INV, esta última no perdió protagonismo, convirtiéndose en su brazo ejecutor. El sustancial aumento de recursos que se vio obligada a gestionar provocó su reestructuración. Francisco de Asís Cabrero fue designado arquitecto jefe de la organización, a la que imprimió un cambio de rumbo orientado a acabar con el oficialismo y la burocracia.

Otro de los problemas que el gobierno abordó fue el de las regulaciones legales, que habían demostrado su inadecuación a las necesidades y disponibilidades de la administración. En

\footnotetext{
2 «Casa baja», de una a tres plantas; «casa media», de cuatro o cinco; y «casa alta», por encima de seis.
} 
julio de 1954 se aprobó la Ley de Vivienda de Renta Limitada, que pretendía corregir los desajustes provocados por sus predecesoras, la Ley de Viviendas Protegidas (1939) y la Ley de Viviendas Bonificables, ambas derogadas. La nueva ley permanecería en vigor hasta mediados de la década de 1960, por lo que su impacto en la definición de los polígonos residenciales fue enorme: estableció los instrumentos necesarios para materializarlos, fijó los procedimientos para acceder a los todavía escasos materiales de construcción, reguló los créditos bancarios y definió incentivos fiscales para atraer a la iniciativa privada (hasta entonces poco interesada en el tema).

Estos cambios legislativos recogieron y oficializaron las reflexiones que se habían producido en la etapa 1949-1953, inicialmente desatendidas por el régimen. Clave para ello fue la publicación, en 1955, de un texto legal complementario a la Ley de Vivienda de Renta Limitada: el Reglamento de Renta Limitada, que venía a sustituir a las amplísimas y rígidas ordenanzas del INV. Si bien su función era establecer prescripciones técnicas y constructivas, varios de sus artículos tenían un marcado carácter arquitectónico. En ellos se aludía a conceptos como «normalización» o "planta tipo», se planteaban cuestiones referentes a costes y superficies... en definitiva, se asociaba la vivienda social a la denominada «vivienda funcional» moderna.

Para afrontar el reto de construir viviendas dignas con superficies y presupuestos mínimos, José Fonseca, arquitecto coordinador del INV, redactó unas rigurosas Ordenanzas Técnicas y Normas Constructivas que llevaban al límite el concepto de «mínimo existencial»: salones de $14 \mathrm{~m}^{2}$, dormitorios de $6 \mathrm{~m}^{2}$, cocinas de entre 4 y $6 \mathrm{~m}^{2}$ y aseos de $1 \mathrm{~m}^{2}$, todo ello en el consolidado tipo de tres dormitorios y $42 \mathrm{~m}^{2}$ de superficie útil. Se establecían, además, una serie de premisas: todas las habitaciones debían contar con luz y ventilación directas, los dormitorios no podían servir como zona de paso, el acceso a baños y aseos debía producirse desde vestíbulos o pasillos, etc. Por último, había prescripciones de tipo urbanístico: no construir en cascos históricos y superar la pequeña escala, desaconsejándose conjuntos de menos de veinticinco unidades. Muchas de las convenciones que habían guiado los diseños de la etapa anterior quedaban así fuera de la ley. A las ordenanzas de Fonseca se sumaron las Instrucciones Complementarias para la Redacción del Proyecto, dictadas por Cabrero para la OSH (Figura 2). En este caso se prohibían los bloques cerrados con patios interiores y se recomendaban los bloques abiertos, agrupados en U, en peine o en línea. Se mencionaba, por primera vez, la tipología que finalmente se impondría: el «bloque en $\mathrm{H}$ » (10).

Era evidente que la administración había cambiado de actitud. El INV había decidido modernizar su política de vivienda. El Pacto Americano, que incluía programas de formación de técnicos españoles, posibilitó que algunos jóvenes arquitectos acudieran a Estados Unidos para conocer las bases técnicas de su arquitectura. Esta experiencia les animó a multiplicar esfuerzos por superar la cultura artesanal e incorporar el campo de la edificación al proceso de industrialización del país. En este caso, sin embargo, Valero Bermejo no se mostró receptivo. Su visión pragmática de la realidad le llevó a desestimar esta posibilidad, convencido de que optar por cuestiones como la prefabricación implicaba prescindir de una numerosa mano de obra, lo que agravaría las ya de por sí alarmantes tasas de desempleo. El Director General del INV lo tenía claro: su apuesta por la modernización de la vivienda social se circunscribía a la racionalización de la planta y la normalización de algunos componentes constructivos, no a la industrialización del proceso. Descartada la prefabricación, las reflexiones los arquitectos se centraron en la tipificación de los componentes del edificio (puertas, ventanas, etc.) y la normalización del mobiliario.

\subsection{7-1959, la producción}

En la segunda mitad de la década de 1950, y a pesar de los esfuerzos realizados en los años anteriores, la magnitud del problema de la vivienda se hizo insostenible: el déficit se cifraba en un millón y las chabolas superaban las cuatrocientas mil. Las autoridades decidieron cambiar de estrategia, quebrando la interesante trayectoria iniciada en 1954: si en la etapa de la experimentación, la tensión entre calidad y cantidad basculó en favor de la primera, ahora la apuesta sería por la segunda. De lo que se trataba era de producir más, y ello exigía altas dosis de pragmatismo.

La meta de la productividad obligó, una vez más, a reestructurar el aparato legislativo y administrativo, una empresa que se saldó con dos hitos: la aprobación de la Ley del Suelo (1956) y la creación del Ministerio de la Vivienda (1957). La primera, que estaría en vigor hasta su modificación en 1975, indujo una revolución conceptual en el urbanismo español: la planificación del crecimiento urbano fue confiada a una concatenación de Planes Parciales asociados a áreas unitarias. Se
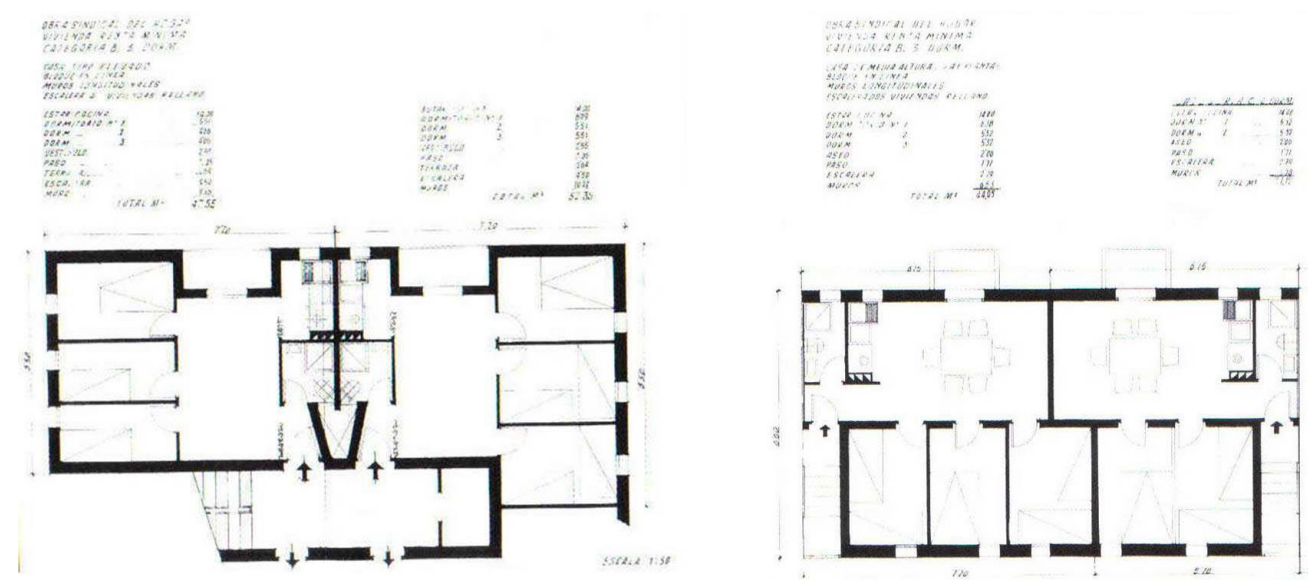

Figura 2. OSH: plantas tipo de 47 y $44 \mathrm{~m}^{2}(4)$. 
preparaba así el terreno para los grandes polígonos de vivienda de las siguientes décadas. El Ministerio de la Vivienda, por su parte, acabaría con uno de los vicios de la política residencial española: la fragmentación administrativa. A partir de 1957 todas las gestiones se canalizarían a través de él, lo que impuso un cambio de protagonistas. Al frente del mismo fue nombrado José Luis Arrese (11), mientras que en el INV Luis Valero Bermejo, el artífice de la etapa de la experimentación, fue sustituido por Vicente Mortes.

Arrese confió la construcción de viviendas sociales a la empresa privada, una intención ya apuntada por la Ley de Vivienda de Renta Limitada de 1954 pero nunca materializada (12). El panorama ahora era diferente. El aumento de la competencia y la productividad había acabado con el tradicional desinterés de aquélla por el sector. Eso sí, los nuevos protagonistas (Urbis, Constructora Peninsular, etc.) exigían rentabilidad, y ello suponía cambiar los modelos arquitectónicos con los que se había estado experimentando hasta entonces, "casa baja» y «casa media», por otro mucho más rentable, «casa alta». El bloque en $\mathrm{H}$ de hasta 13 plantas de altura fue consagrado como tipología oficial de los polígonos residenciales (Figura 3). Separándolos entre sí cuarenta metros se conseguían densidades de hasta 2.000 habitantes por hectárea. Si tenemos en cuenta que la media de 4,24 viviendas por bloque de 1947 se convirtió en 40 ó 50 a finales de la década de 1950, seremos conscientes de la casi traumática mutación que experimentaron las ciudades españolas en esa etapa.

Así quedó perfilado el modelo de polígono que conocemos hoy en día. En el verano de 1959 el gobierno hizo público el Plan de Estabilización y Liberalización, que abría la etapa económica más floreciente del franquismo. En el campo que nos ocupa, este espacio de tiempo se correspondió con la construcción de los grandes polígonos residenciales. En 1961 se aprobó un nuevo Plan Nacional de la Vivienda que pretendía construir más de 3.700.000 unidades habitacionales en el periodo 1961-1976. Sus prescripciones dejaban claro que el precepto de la calidad había sido definitivamente suplantado por el de la cantidad. Los polígonos de los años 1960 se materializarían como operaciones gigantescas (30o hectáreas de media), situadas en los extrarradios, sin responder a ningún modelo de ciudad (de una tajada se proyectaban, urbanizaban y edificaban), y con precariedad de equipamientos escolares, comerciales, recreativos y de zonas verdes, equipamientos que, aunque prescritos por la Ley del Suelo, se relegaban a etapas posteriores que nunca llegaron.

\section{CAMBIO SOCIAL CONTEMPORÁNEO Y OBSOLESCENCIA DE LOS POLÍGONOS RESIDENCIALES}

Entre finales de los años 1980 y comienzos de los 1990 se produjo en España un cambio humano sin parangón en Europa, lo que se explica por las especificidades históricas del país. El fin de la dictadura y la entrada en la Unión Europea desató procesos de todo tipo: inmigración, movilidad geográfica, aparición de nuevos modelos de familia, modificaciones en la pirámide de edad, hundimiento de la natalidad... Esta mutación social impactó en las tipologías arquitectónicas de los polígonos, que fueron diseñadas para alojar una clase obrera inserta en una sociedad industrial, moral y culturalmente pautada por una dictadura. El perfil de la persona actualmente demandante de vivienda no tiene nada que ver con aquel grupo humano, lo que apunta la importante cuota de responsabilidad que las tipologías arquitectónicas tienen en la actual obsolescencia de los polígonos.

Para contrastar esta hipótesis hemos trasladado a ellos los requisitos y expectativas residenciales de la sociedad contemporánea. El principal estudio utilizado como referencia ha sido Habitar el Presente. Vivienda en España: sociedad, ciudad, tecnología y recursos (2006), realizado por Josep María Montaner y Zaida Muxí para el Ministerio de la Vivienda. El protagonismo que se le concede se justifica por tratarse de uno de los escasos trabajos realizados por arquitectos y que ofrece una visión panorámica de la vivienda contemporánea en España, abarcando cuestiones sociales, urbanas, tecnológicas y energéticas (13). Además, la primera de las secciones de este estudio, «sociedad», pone en contacto las dos componentes de nuestra hipótesis de partida: modos de habitar y tipologías arquitectónicas.

Tras detectar los desencuentros existentes entre las viviendas de los polígonos y las necesidades contemporáneas, hemos seleccionado aquéllos de raíz físico-espacial, donde las tipologías arquitectónicas son determinantes. Dos de ellos son cuantitativos, dimensión y funcionalidad, mientras que otros son esencialmente cualitativos, derivados de cambios culturales y de formas de vida.

\subsection{Dimensión de las viviendas}

En esta cuestión entran en liza tres parámetros: la superficie de las viviendas, el número de personas que la habitan y el
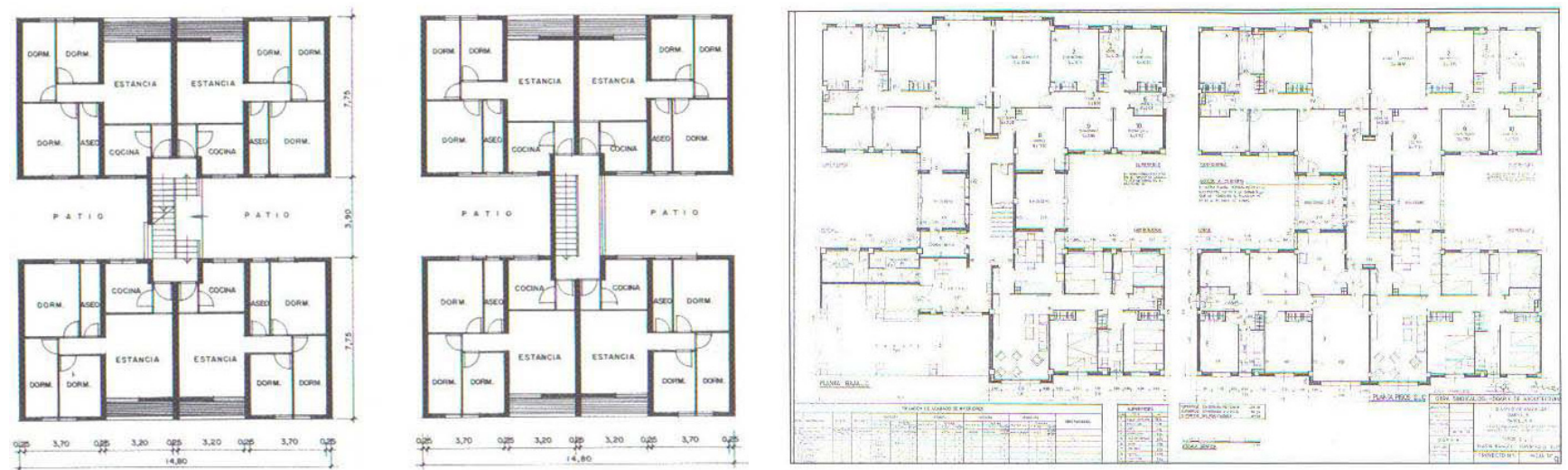

Figura 3. Polígonos madrileños de las décadas de 1960 y 1970: Moratalaz (1968) y San Blas (1973). Las plantas evidencian la zonificación funcionalista de la vivienda en áreas de día (salón y cocina) y de noche (dormitorios y baños) (4). 
número de estancias. Por lo que respecta al primero, hemos visto que la reducción de superficies fue un vector constante durante el franquismo. En la etapa de reflexión, Miguel Fisac llegó a proponer unidades de $40 \mathrm{~m}^{2}$ para ocho personas, lo que suponía una media de $5 \mathrm{~m}^{2}$ de superficie útil por habitante. El Plan de Viviendas de Tipo Social (1954) estableció un estándar que recogerían muchas otras normativas: $42 \mathrm{~m}^{2}$ para una vivienda de tres dormitorios, es decir, unos $7 \mathrm{~m}^{2}$ por habitante. Posteriormente, el Plan Nacional de la Vivienda de 1961 elevaría esa superficie a $50 \mathrm{~m}^{2}, 8,3 \mathrm{~m}^{2}$ por habitante, pero es de reseñar que nunca se alcanzaron los $10 \mathrm{~m}^{2}$ por habitante fijados como «mínimo existencial» en la Alemania de entreguerras.

El segundo y tercer parámetros, número de personas y estancias, están interrelacionados. Según el censo realizado por el Instituto Nacional de Estadística en 1958, el porcentaje de habitantes por vivienda era entonces de 4,51. No existen datos sobre el caso concreto de las sociales, pero es de suponer que era bastante más elevado, dado que estaban mayoritariamente habitadas por matrimonios en edad de procrear. La media de cuatro hijos por familia explica que el tipo más extendido fuera el de tres dormitorios. Así lo prescribió el Plan de Viviendas de Tipo Social de 1954 y el Plan Nacional de Vivienda de 1955. El Plan de 1961 llegaría a otorgarle «prioridad absoluta», aludiendo a la excepcionalidad de las viviendas de dos, cuatro o cinco dormitorios (las de uno ni se mencionaban).

Según el estudio de Montaner y Muxí (14), en la contemporaneidad la superficie media y el número de habitantes por vivienda han disminuido. El mayor crecimiento se ha producido en los hogares unipersonales, básicamente porque los jóvenes han cambiado sus pautas de emancipación y se ha incrementado la autonomía residencial de los mayores. También se han disparado las parejas sin hijos que cuentan con dos ingresos. El resultado es que, actualmente, el $20 \%$ de los hogares españoles son unipersonales, el $25 \%$ está formado por dos personas, y los de tres y cuatro miembros suponen el 21 \% cada uno (a partir de ahí, la proporción cae radicalmen-
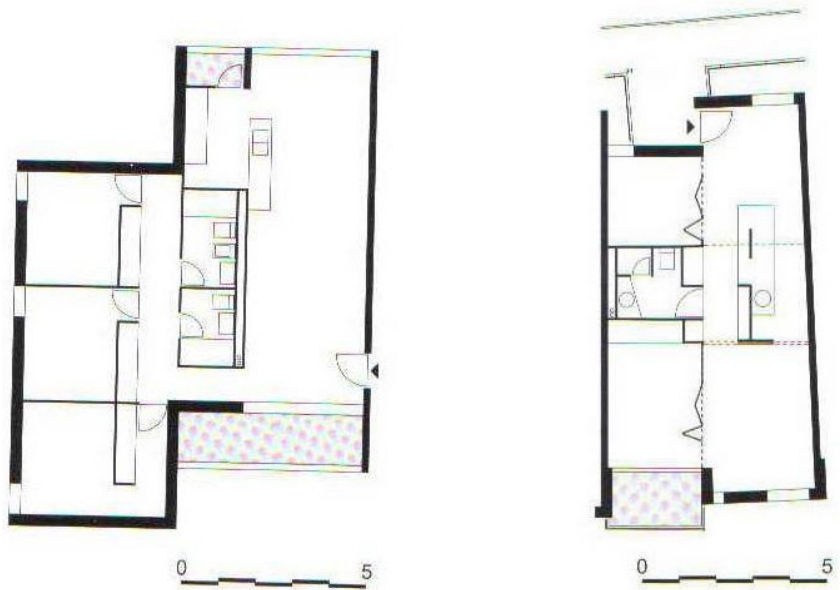

Figura 4. Ejemplos de flexibilidad e hibridación de usos en la vivienda contemporánea. En la planta de la izquierda (viviendas en Rabassa, de L. F. Herrero, M. Pérez y C. Calle) las jerarquías han sido anuladas: los dormitorios son de similar dimensión, y armarios y baños abren a espacios comunes. En la planta de la derecha (viviendas en Mataró, de Durán \& Grau Arquitectes), una potencial habitación de trabajo ha sido segregada de las estancias de uso doméstico y vinculada al recibidor (14). te: 7,7 \% de hogares de cinco y 2,5 \% de seis). En conclusión, las necesidades actuales apuntan hacia viviendas de uno y dos dormitorios.

\subsection{Funcionalidad de las viviendas}

Desde el punto de vista de la funcionalidad, dos son los factores que ab undan en la crisis tipológica que nos ocupa: la jerarquización y la monofuncionalidad.

El modelo familiar franquista era muy estable. La sociedad estaba regida por los preceptos del nacional-catolicismo, que prohibían el divorcio y condenaban cualquier tipo de convivencia alternativo a la familia tradicional. La vocación de permanencia de esta última se proyectaba sobre las plantas de las viviendas. Los dormitorios estaban jerarquizados: el de mayor superficie para la pareja, los pequeños para los hijos. Cuando se trataba de viviendas de más alto nivel, esa jerarquía se reforzaba dotando al dormitorio de matrimonio de armario empotrado o baño privado.

Tal como señalan Montaner y Muxí, en la contemporaneidad la composición de los hogares se modifica a menudo y de manera brusca, debido a volatilidad de las relaciones interpersonales. La vivienda ha de adaptarse a esta condición existencial, lo que traslada al proyecto arquitectónico una máxima: la flexibilidad. Las jerarquías han de reducirse al mínimo: los dormitorios deben ser de tamaño semejante, los baños de uso no exclusivo y los armarios empotrados abrir hacia espacios comunes.

La monofuncionalidad, por su parte, respondía a los preceptos de la arquitectura moderna, que fueron trasladados a los polígonos por los reglamentos, instrucciones y ordenanzas de la Ley de Vivienda de Renta Limitada de 1954. La presunción del uso exclusivamente residencial de la vivienda permitía dividirla en zonas de día (salón y cocina, orientados a poniente y asociados a la entrada) y de noche (dormitorios y baños, orientados a levante y relegados a la parte más privada de la casa).

La creciente importancia del teletrabajo y el aumento de los profesionales que desarrollan sus labores desde casa son incompatibles con la monofuncionalidad residencial, obligando a prever espacios de producción que puedan funcionar de manera segregada del resto de la vivienda, espacios dotados de baño y recibidor, e independientes de las estancias privadas (Figura 4).

\subsection{Cambios culturales y de forma de vida}

Los polígonos residenciales fueron diseñados para una sociedad de masas: unidades familiares compuestas por progenitores en edad madura; que compartían nacionalidad, raza, religión y cultura; y donde el hombre trabajaba en la industria o la construcción, y la mujer en las tareas domésticas. Su imagen urbana reflejaba especularmente esta homogeneidad: interminables sucesiones de bloques funcionalmente organizados, dimensionalmente modulados, estéticamente estandarizados y heliotérmicamente orientados, bloques que albergaban ultratipificadas viviendas cuyas variaciones se limitaban a la superficie y el número de dormitorios.

Los «estudios culturales», una rama del pensamiento crítico que aboga por analizar los procesos de producción de cultura 
de las clases subalternas, han denunciado que tras la aplastante uniformidad físico-espacial de actuaciones de este tipo se esconden estrategias de segregación que priman el papel del hombre occidental y de edad madura, relegando o excluyendo a mujeres, inmigrantes, jóvenes, ancianos, etc 3 . Este postulado nos ha servido para analizar la vertiente cualitativa de los desencuentros polígonos-sociedad contemporánea, la que tiene que ver con cambios de valores y de formas de vida.

La primera cuestión que hemos abordado desde este punto de vista ha sido la del género. Los polígonos construidos durante el franquismo fueron proyectados para familias patriarcales, dependientes del único salario del padre y tuteladas por la madre. Aunque la vivienda era el «espacio de la mujer» y el espacio público el del hombre, esta identificación no estaba orientaba a su realización personal, sino a posibilitar su rol como gestora de la cotidianeidad familiar. En una sociedad abrumadoramente machista, la estancia femenina por excelencia era la cocina, que era convenientemente segregada del resto de la vivienda y reducida a la mínima expresión (como vimos, las Ordenanzas Técnicas y Normas Constructivas del INV le prescribían una superficie de 4 a $6 \mathrm{~m}^{2}$, dependiendo de que contaran o no con lavadero). Por el contrario, Montaner y Muxí defienden que, para incitar a compartir el trabajo en la cocina, su dimensión ha de ser generosa y se debe favorecer su visibilidad, integrándola en el comedor o el salón.

Otro de los temas analizados desde la óptica de los estudios culturales ha sido la diversidad étnica, nacional y religiosa. Si tenemos en cuenta que el 77,11 \% del crecimiento demográfico español entre 2001 y 2007 se debió a la llegada de población extranjera, y que este sector es uno de los principales demandantes de viviendas sociales, concluiremos que también en la investigación que nos ocupa deba ocupar un lugar preferente. Las diseñadas por los arquitectos del Movimiento Moderno obedecían a criterios eminentemente funcionalistas. Ello plantea un problema cuando son ocupadas por personas provenientes de culturas no occidentales, para las que cuestiones de tipo simbólico-religioso pueden ser sumamente importantes. Un ejemplo de ello es la comunidad musulmana. En Holanda se ha ensayado la división de la vivienda en zonas masculinas y femeninas, lo que permite un uso normalizado del espacio doméstico en momentos de visita de personas ajenas al ámbito familiar (Figura 5).

Por último, el tercer factor de exclusión apuntado por los estudios culturales que consideramos importante para nuestra investigación, es la edad. En este caso, los grupos humanos tradicionalmente segregados se sitúan en los dos extremos vitales: ancianos y jóvenes. Ambos son sumamente importantes para la recuperación de los polígonos. Los primeros porque son su presente, ya que la generación que se trasladó a ellos en los años 1960 y 1970 cuenta actualmente con una edad avanzada. Los jóvenes porque son su futuro, un nicho de mercado que se ha disparado en las últimas décadas por múltiples razones: una más temprana emancipación familiar, aumento de la movilidad geográfica por trabajo o estudios, etc. La adaptación de las viviendas de los polígonos a los requisitos de estos grupos poblacionales tiene una innegable componente cuantitativa: resolver los problemas de movilidad es clave para los ancianos; la flexibilidad (para poder compartir la vivienda) y la hibridación de usos (para poder trabajar en ella) son esenciales para los jóvenes. Pero también existen necesidades de tipo cualitativo derivadas de su singular forma de vida, muy tendente al colectivismo: salones de encuentro, servicios comunitarios, espacios de ocio, áreas de co-working, zonas deportivas, etc. (Figura 6).

\section{CONCLUSIONES}

En el primer apartado del artículo se ha analizado la evolución del proceso de definición de las tipologías arquitectónicas de los polígonos residenciales; en el segundo se ha contrastado la información resultante con un estudio sobre la
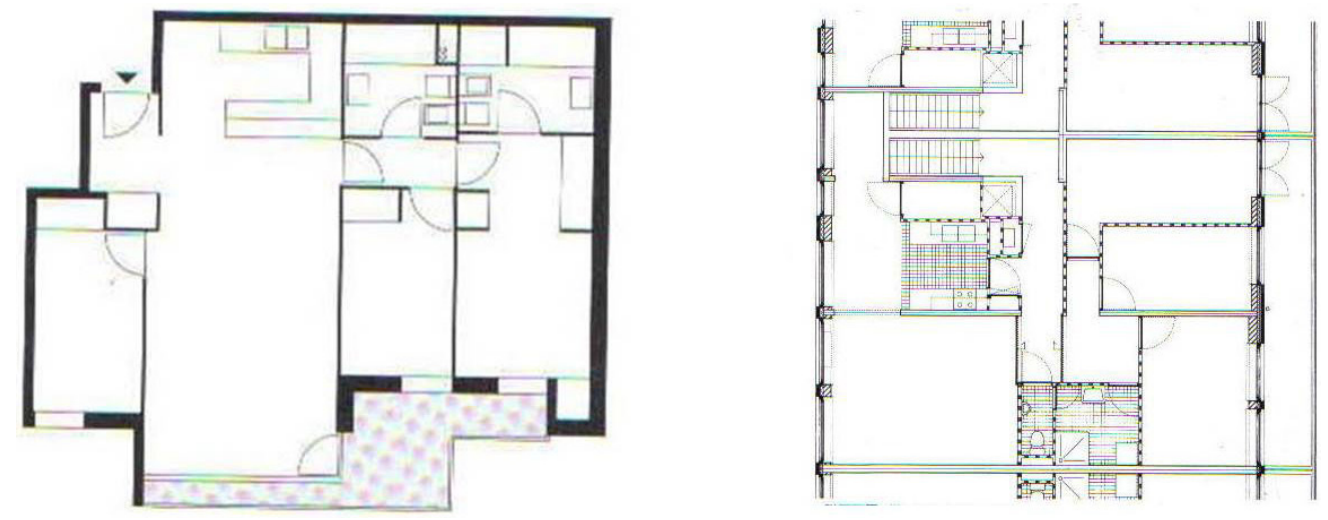

Figura 5. Políticas de género y adaptación cultural en la vivienda contemporánea. En la planta de la izquierda (viviendas en Barcelona, de C. Ferrater), la cocina ha sido integrada en el salón (14).

La planta de la derecha (viviendas en La Haya, de A. Siza), ha sido subdividida en dos mitades susceptibles de ser utilizadas como espacios de género. (A+U (1989), Alvaro Siza 1954-1988, Tokio, A+U Publishing).

\footnotetext{
3 La recurrencia a los estudios culturales se justifica por el compromiso de insertar la presente investigación en un sistema de valores socialmente comprometido. En su aplicación a la arquitectura, el punto de partida de los estudios culturales es fiel a los planteamientos del pensamiento crítico: el espacio arquitectónico no es algo neutro u objetivo, sino un ente predispuesto para que el poder ejerza su dominio sobre las clases subalternas. La novedad que introducen es el reconocimiento de que las lógicas subyacentes tras estas prácticas de imposición y subordinación no son únicamente de clase; también en torno a la raza, la sexualidad, el género, la edad o la enfermedad se han articulado estrategias segregacionistas.
} 


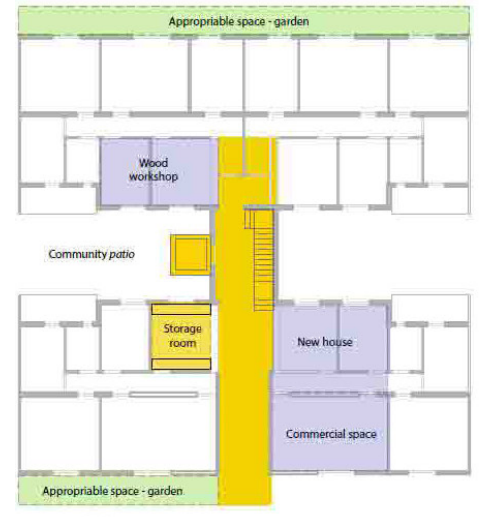

Ground floor

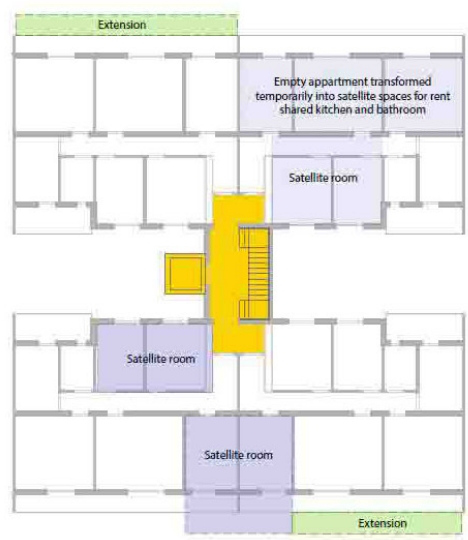

Third floor

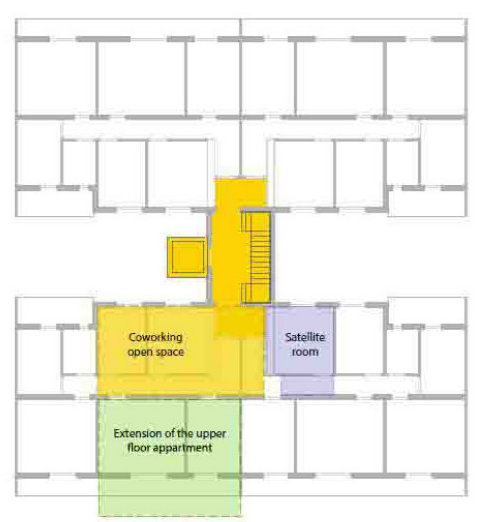

First floor

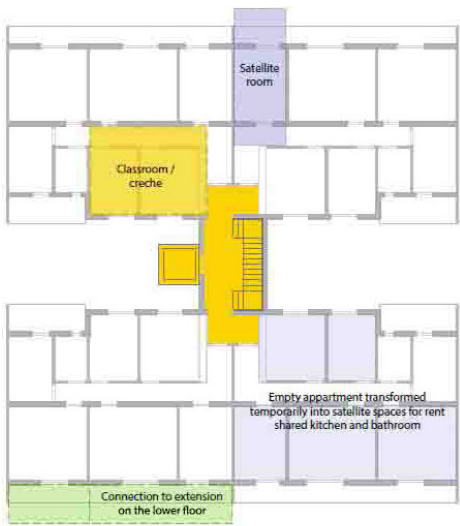

Second floor

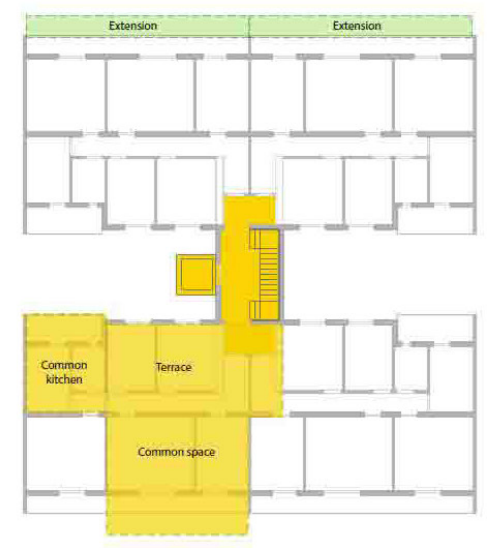

Fourth floor

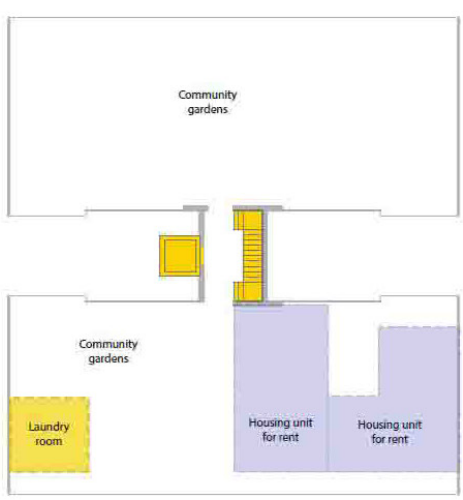

Rooftop

Figura 6. Reconversión de las zonas comunes de un bloque en H en espacios colectivos. Concurso UN-Hábitat para la revitalización de conjuntos de viviendas sociales: Propuesta para el barrio de Orba, Valencia, de M. T. García y G. Navarrete. (http://masshvousingcompetition.org/results/entry/578).

vivienda contemporánea, lo que ha permitido evidenciar los desajustes entre aquéllas y los requisitos de nuestra sociedad: reducido espacio vital, exceso de dormitorios, rigidez distributiva, monofuncionalidad, inadecuación de espacios como la cocina y despersonalización cultural.

Mayoritariamente, estos conflictos derivan de dos aspectos vinculados a la tipología arquitectónica: la superficie y la distribución. La obsolescencia de la primera se debe a una mayor exigencia de espacio personal, asociada al aumento del nivel de vida. Los 7-8 $\mathrm{m}^{2}$ útiles por habitante de los años 1950 se han convertido actualmente en unos $13 \mathrm{~m}^{2}$, oscilando entre los $9 \mathrm{~m}^{2}$ de las viviendas protegidas de cuatro dormitorios y los $20 \mathrm{~m}^{2}$ de las de uno.

Por lo que respecta a la distribución, el desencaje es más poliédrico, diferenciándose una dimensión conceptual y otra específica. La primera es responsable de la falta de flexibilidad. Desde el punto de vista habitacional, aspectos como la jerarquización de los dormitorios dificultan la adaptación de la vivienda a nuevas circunstancias personales o familiares. Desde el punto de vista funcional, la vinculación de salones y cocinas con la entrada relega las habitaciones potencialmente utilizables como espacios de trabajo, básicamente los dormitorios, a zonas poco accesibles, impidiendo la autonomía del ámbito productivo con respecto al doméstico. Por otro lado, la distribución estrictamente funcionalista de este tipo de viviendas obstaculiza la conciliación con las necesidades simbólico-representativas de determinadas comunidades étnico-religiosas. La división en zonas femeninas y masculinas, ensayada para la musulmana, exigiría conectar las cocinas con los dormitorios y duplicar los baños, de manera que cada espacio de género contase con uno.

La dimensión específica de la crisis distributiva de las viviendas de los polígonos se evidencia en la obsolescencia de dos tipos de estancia; dormitorios y cocinas. Los primeros son excesivos en número pero deficitarios en superficie, si bien es cierto que el desencaje existente entre los tres dormitorios de media que poseen las viviendas de los polígonos y los uno o dos que se requieren en la contemporaneidad, se complementa con la mayor exigencia de espacio disponible por persona. Ello posibilita que el extendido tipo de $42 \mathrm{~m}^{2}$ de superficie útil para tres dormitorios se reconvierta en una vivienda de un dormitorio, a la que la actual normativa exige un mínimo de $40 \mathrm{~m}^{2}$. Las cocinas, por su parte, contravienen las políticas de género por dos razones: su escasísima dimensión y su segregación de las zonas nobles de la vivienda, si bien es cierto que la fusión de estar, comedor y cocina fue prescrita por propuestas y regulaciones de los años 1950 (Plan de Viviendas de Tipo Social, Ley de Vivienda de Renta Limitada, etc.).

La inadecuación de superficies y distribuciones pone en cuestión elementos esenciales de la materialidad arquitectónica. La tabiquería es el principal de ellos, un problema que se agudiza cuando se ven implicados los núcleos húmedos, 
difícilmente reubicables debido a su conexión a los sistemas verticales de suministro y evacuación de aguas. A menudo, además, la precariedad de los sistemas estructurales y constructivos de la época congela la distribución en el tiempo, como ocurre en el caso de los edificios de doble crujía y muros de carga. También la fachada exige ser reformulada, tanto por la vinculación de sus huecos con las habitaciones como por su condición de contenedor de la escasa superficie disponible. Las soluciones habitualmente ensayadas para afrontar este problema han consistido en la ampliación del perímetro de la vivienda con módulos adosados exteriormente, lo que implica una auténtica mutación de la fachada (paradigmática fue la intervención de Lacaton \& Vassal en la Tour Bois-lePrête, París, 2011).

Frente a estas debilidades, los polígonos ofrecen algunas fortalezas que escasean en otras zonas de la ciudad. La principal es la abundancia de lugares vacantes, resultado del modelo urbano al que se adscribieron: áreas verdes y espacios públicos infrautilizados y a menudo abandonados al automóvil (recordemos que la distancia entre bloques llegaba a alcanzar los $40 \mathrm{~m}$ ); o plantas bajas no construidas y frecuentemente valladas para evitar usos no deseados. Estas generosas extensiones de terreno pueden ser colonizadas con servicios y actividades colectivas, que son muy propias de la forma de vida de los jóvenes y ancianos. La vivienda social recuperaría así una dimensión colectivista que estuvo muy presente en su génesis en los años 1920.

Con estas conclusiones consideramos demostrada la hipótesis de partida de este artículo: que las tipologías arquitectónicas son uno de los principales factores del actual estado de obsolescencia de los polígonos residenciales construidos entre 1950 y 1976. También han puesto en evidencia la magnitud del esfuerzo humano y económico que exige su renovación física. Ello no quiere decir que no entendamos que la sociedad europea no deba asumir ésta como una tarea prioritaria. Apostar por los polígonos residenciales es apostar por un desarrollo urbano sostenible; por un modelo social no especulativo ni gentrificador; por la preservación de la memoria colectiva del siglo $\mathrm{xx}$, de la sociedad industrial, de la clase obrera. Por ello creemos que vale la pena adaptarlos a las necesidades socioculturales contemporáneas, tal como en su momento hicimos con los cascos históricos.

\section{REFERENCIAS}

(1) Sambricio, C. (2004). Madrid, vivienda y urbanismo: 1900-196o, Madrid: Akal.

(2) Sambricio, C. (Coordinador). (1999). La vivienda en Madrid en la década de los 5o. El Plan de Urgencia Social, Madrid: Electa.

(3) Ferrer i Aixalà, A. (1996). Els poligons de Barcelona, Barcelona: Universitat Politècnica de Catalunya.

(4) Sambricio, C. (Editor). (2003). Un siglo de vivienda social 1903-2003, Madrid: Nerea.

(5) Sambricio, C., Sánchez Lampreave, R. (Editores). (2008). 100 años de historia de la intervención pública en la vivienda y la ciudad, Madrid: Asociación Española de Promotores Públicos de Vivienda y Suelo (AVS).

(6) Álvarez, E. (1961). Viviendas amparadas por el estado. Recopilación de las legislaciones vigentes sobre viviendas baratas y económicas, Madrid: Boletín Oficial del Estado.

(7) Bergera, I. (2008). Obra Sindical del Hogar: tres décadas de vivienda social. En Sambricio, C., Sánchez Lampreave, R. (Editores), 100 años de historia de la intervención pública en la vivienda y la ciudad (pp. 121-143). Madrid: Asociación Española de Promotores Públicos de Vivienda y Suelo (AVS).

(8) Azpiri, A. (2000). La aportación del Colegio Oficial de Arquitectos Vasco-Navarro a la V Asamblea Nacional de Arquitectos, en el año 1959. En: Pozo, J.M. (Coord.), Los años 50: la arquitectura española y su compromiso con la historia (pp. 101-107). Pamplona: Escuela Técnica Superior de Arquitectura de la Universidad de Navarra.

(9) Sambricio, C. (2000). La vivienda española en los años 50. En: Pozo, J.M. (Coord.), Los años 5o: la arquitectura española y su compromiso con la historia (p. 46). Pamplona: Escuela Técnica Superior de Arquitectura de la Universidad de Navarra.

(10) López de Lucio, R. (2003). De la manzana cerrada al bloque abierto. En: Sambricio, C. (Ed.), Un siglo de vivienda social 1903-2003 (tomo II) (p.161-166). Madrid: Nerea.

(11) Arrese, J. L. (1959). Política de vivienda (textos y discursos), Madrid: Ministerio de la Vivienda.

(12) Roch, F. (2003). El sector privado y la construcción de viviendas sociales. En: Sambricio, C. (Ed.) (2003), Un siglo de vivienda social 1903-20o3 (tomo II) (pp. 170-173). Madrid: Nerea.

(13) Peremiquel, L. (2000). Vivienda, innovación y proyecto. Necesidades, nuevas tecnologías y estrategias proyectuales, Barcelona: Collegi d'Arquitectes de Catalunya.

(14) Montaner, J. M., Muxí, Z. (2006). Habitar el Presente. Vivienda en España: sociedad, ciudad, tecnología y recursos, p. 20-57, Madrid: Ministerio de Vivienda. 